\title{
The effects of isokinetic knee extensor and flexor strength on dynamic stability as measured by functional reaching
}

\author{
Robert G. Lockie*, Adrian B. Schultz, Samuel J. Callaghan and Matthew D. Jeffriess \\ Exercise and Sport Science Department, School of Environmental and Life Sciences, University of Newcastle, \\ Ourimbah, NSW, Australia
}

Received 15 August 2012

Accepted 21 December 2012

\begin{abstract}
.
BACKGROUND: Team sport athletes require dynamic stability in unilateral activities for their sports, which necessitates some degree of knee flexion and extension strength.

OBJECTIVE: To analyze the possible association of knee extension and flexion strength with dynamic stability, as measured by the Star Excursion Balance Test (SEBT).

METHODS: Sixteen male team sport athletes completed the SEBT, which involves a series of unilateral squats with the subject maximally reaching with the other leg in eight directions. Knee muscle strength was measured isokinetically both concentrically $\left(60^{\circ} \% \mathrm{~s}, 180^{\circ} \% \mathrm{~s}, 240^{\circ} \% \mathrm{~s}\right)$ and eccentrically $\left(30^{\circ} \%\right)$. Subjects were divided into better and lesser groups based on mean functional reach distance. A 1 -way analysis of variance $(p \leqslant 0.05)$ determined between-group differences in reach distances and relative torque.

RESULTS: Subjects with better dynamic stability generated greater knee extensor torque concentrically at $180^{\circ} / \mathrm{s}$ for the right leg, and at all speeds for the left leg. The effects of knee strength were particularly noteworthy for the left leg, as subjects with better dynamic stability reached significantly further across all 8 directions.

CONCLUSION: The results indicate that greater knee extensor strength may enhance unilateral dynamic stability in team sport athletes.
\end{abstract}

Keywords: Star Excursion Balance Test, relative torque, unilateral strength, dynamic balance, bilateral differences

\section{Introduction}

Many different sporting activities require an athlete to possess dynamic stability. Dynamic stability has been defined as the ability to maintain balance while transitioning from a dynamic to static state [38], or being able to perform a functional task without compromising any part of the supporting leg $[35,37]$. Essen-

*Corresponding author: Robert Lockie, School of Environmental and Life Sciences, University of Newcastle, PO Box 127, Ourimbah, NSW 2258, Australia. Tel.: +61 24349 4428; Fax: +61 24348 4145; E-mail: robert.lockie@newcastle.edu.au. tially, this means an athlete can maintain a more stable center of mass when performing sport-specific movements. Some examples of this include effectively completing agility-based movements that involve decelerating and changing direction [5], or maintaining a stable base of support when performing an action such as a tennis or badminton stroke [35]. There are several laboratory-based protocols that can be used to assess dynamic stability. One of the more popular assessments is the Star Excursion Balance Test (SEBT) [32, 34].

The SEBT involves a subject adopting a unilateral stance and performing a series of single-leg squats 
while attempting maximal reach with the other leg in eight different directions; three anterior, two lateral, and three posterior (Fig. 1) [9,34]. The subject's stability is challenged, in that the body's center of mass is moved in relation to the base of support every time a reach is attempted [16]. A greater functional reach, measured in relation to the subject's leg length, provides an indication of greater dynamic stability. During these excursions, there is co-contraction of the knee extensors and flexors of the stance leg to assist with maintaining stability [9]. This indicates the importance of the knee extensors and flexors to dynamic stability through functional reaching. Greater strength in these muscles could positively impact dynamic stability.

The relationship between lower-limb strength and dynamic stability has tended to have more of a clinical focus in the research literature [14,26,29,32]. For example, knee extensor strength has been related to better dynamic stability in elderly persons with functional limitations [26], and with Parkinson's disease [29]. However, there has been minimal to no analysis of the relationship of leg strength to dynamic stability in healthy athletes who need this physical trait in their chosen sport. This is a situation that needs to be rectified, given the importance of dynamic stability for athletic performance $[5,35]$, and the need for this capacity to be trained [4]. Documenting which muscle groups are stronger in athletes with better dynamic stability as measured by functional reaching could provide strength and conditioning coaches with pertinent information with which to design training programs to improve this capacity.

To the best of our knowledge, no research has analyzed how the strength of the knee extensors and flexors correlates with the dynamic stability in a unilateral activity such as functional reaching in strength-trained subjects. Therefore, the objective of this study was to determine whether and how greater isokinetic knee extensor and flexor strength is reflected in dynamic stability as measured by the SEBT. It was hypothesized that those subjects with a greater functional reach, and thus greater dynamic stability, would have greater relative torque in the knee extensors and flexors when compared to subjects with a lesser reach.

\section{Method}

\subsection{Subjects}

16 men (age $=23.31 \pm 5.34$ years; height $=1.78$ $\pm 0.07 \mathrm{~m}$; mass $=80.60 \pm 9.89 \mathrm{~kg}$ ) without a his- tory of lower-limb injury volunteered to participate in this study. Subjects were recruited if they: currently participated in a team sport that stressed dynamic balance (e.g. soccer, rugby, basketball, cricket, ice hockey); had a general team sport ( $\geqslant 2$ times/week) and strength training ( $\geqslant 2$ times/week) history extending over the previous year; were currently training for a team sport ( $\geqslant 3$ hours/week) and strength training $(\geqslant 3$ hours/week); and did not have any existing medical conditions, balance disorders, or significant leg pathologies that would compromise study participation. The methodology and procedures used in this study were approved by the University of Newcastle ethics committee, and conformed to the policy statement with respect to the Declaration of Helsinki. All subjects received a clear explanation of the study, including the risks and benefits of participation, and written informed consent was obtained prior to testing.

\subsection{Testing procedures}

Tests were conducted over two separate days, with 48 hours between each testing session. Height and weight were measured on Day 1 . Height was measured barefoot using a portable stadiometer (Seca 213, Ecomed Trading, Australia), while body weight was recorded using electronic digital scales (BF-522, Tanita Corporation, Japan). Day 1 consisted of the SEBT assessment in the biomechanics laboratory. Isokinetic strength testing was conducted on Day 2 in the resistance training laboratory. Subjects were assessed in the same order on both testing occasions.

\subsection{Star Excursion Balance Test (SEBT)}

Dynamic stability was assessed by using the SEBT (Fig. 1). The SEBT has been found to be reliable for assessing dynamic stability [16,33], and the methods used in this study were modified from previous research $[5,13,34]$. The testing grid consisted of eight standard tape measures taped to the laboratory floor, each of which was $120 \mathrm{~cm}$ long. Each tape measure extended from an origin at $45^{\circ}$ increments, which was measured by a goniometer. The middle of the grid was clearly marked with a black marker. The terminology for the excursion direction was based on the direction of reach from the stance leg (Fig. 1). The anterior, anterolateral, and anteromedial directions required the subject to reach in front of the body. For the lateral reach, subjects' abducted the reach leg to the side of their body. When reaching in the posterolateral, poste- 

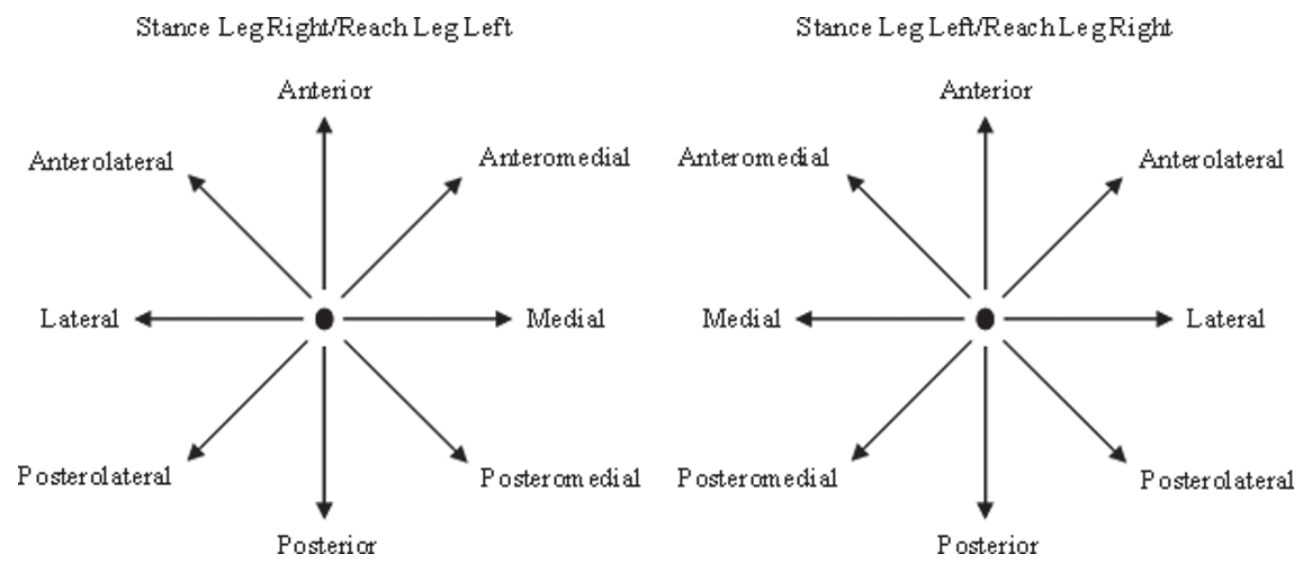

Fig. 1. Reaching directions for each leg during the Star Excursion Balance Test.

rior, and posteromedial directions, the subject reached behind the body. The medial reach involved the subject adducting their stance leg to a position behind the body, before extending the leg medially. These reaches are shown in Fig. 2.

Prior to completing the SEBT, subjects completed 10 minutes of cycling on a bicycle ergometer at a selfselected pace. Subjects were then required to stand on the center marker of the SEBT, with the ankle malleoli aligned with the lateral tape measures. This was visually assessed by the researcher. Subjects then used their free leg to reach about the star, beginning in an anterior direction and working clockwise around the grid. A minimum of three practice trials were used prior to data collection to familiarize subjects to the movements required, and to serve as a warm-up. With each attempt, the subject attempted reach as far as possible along each line and make a light touch on the ground with the most distal part (i.e. the toes) of the reaching leg. The subject then returned the reaching leg to a bilateral stance, without allowing contact to affect overall balance. A researcher noted the reach distance after each excursion attempt. A trial was disregarded if the researcher felt the subject used the reaching leg for an extended period of support, removed the stance leg from the center of the grid, or was unable to maintain balance. The same researcher measured the SEBT for all subjects. The order of the stance leg used during testing was randomized amongst the subject group.

Reach distances were considered relative to the subject's leg length $[13,14]$. Relative reach distances were expressed as a percentage according to the formula relative reach distance $=$ reach distance/leg length $\mathrm{x} 100$. The differences in relative reach distances between the stance legs was also calculated, and derived from the formula stance leg with greater reach distance-stance leg with lesser reach distance/stance leg with greater reach distance $x 100$.

\subsection{Isokinetic strength assessment}

Knee extensor and flexor strength was assessed by isokinetic dynamometry (Humac Norm, CSMI Solutions, USA). The dynamometer was calibrated prior to each testing session by attaching known weights to the calibration arm of the machine and verifying the torque. Protocols were programmed into the computer software prior to testing. Prior to the isokinetic assessment, subjects completed 10 minutes of cycling on an ergometer at a self-selected pace. They were then placed in an upright seated position, and were secured to the seat with shoulder straps, which were fastened in the middle of the chest. The shin pad was adjusted to fit the subject, and the thigh strap was secured $3 \mathrm{~cm}$ above the quadriceps-patella tendon junction. The axis of rotation of the knee joint was determined through palpation of the lateral femoral condyle and aligned to the axis of the dynamometer by adjusting the seat position.

Concentric torque was assessed at three angular velocities: $60 \% \mathrm{~s}, 180 \%$ s, and $240 \%$ s. Eccentric torque was measured at $30 \%$ s. These speeds have been used when analyzing athletic populations [1,8,20,27], and this testing procedure has been established in previous research [24]. The low-range eccentric speed was used because high-velocity lengthening of the muscle imposed by isokinetic dynamometry can be uncomfortable and adversely affect the subject's applied effort $[18,24]$. Contractions were performed through a range of $15-80^{\circ}$ (full extension defined as $0^{\circ}$ ). Testing order progressed from the slowest to the highest speeds [24,39]. Subjects completed all concentric tri- 

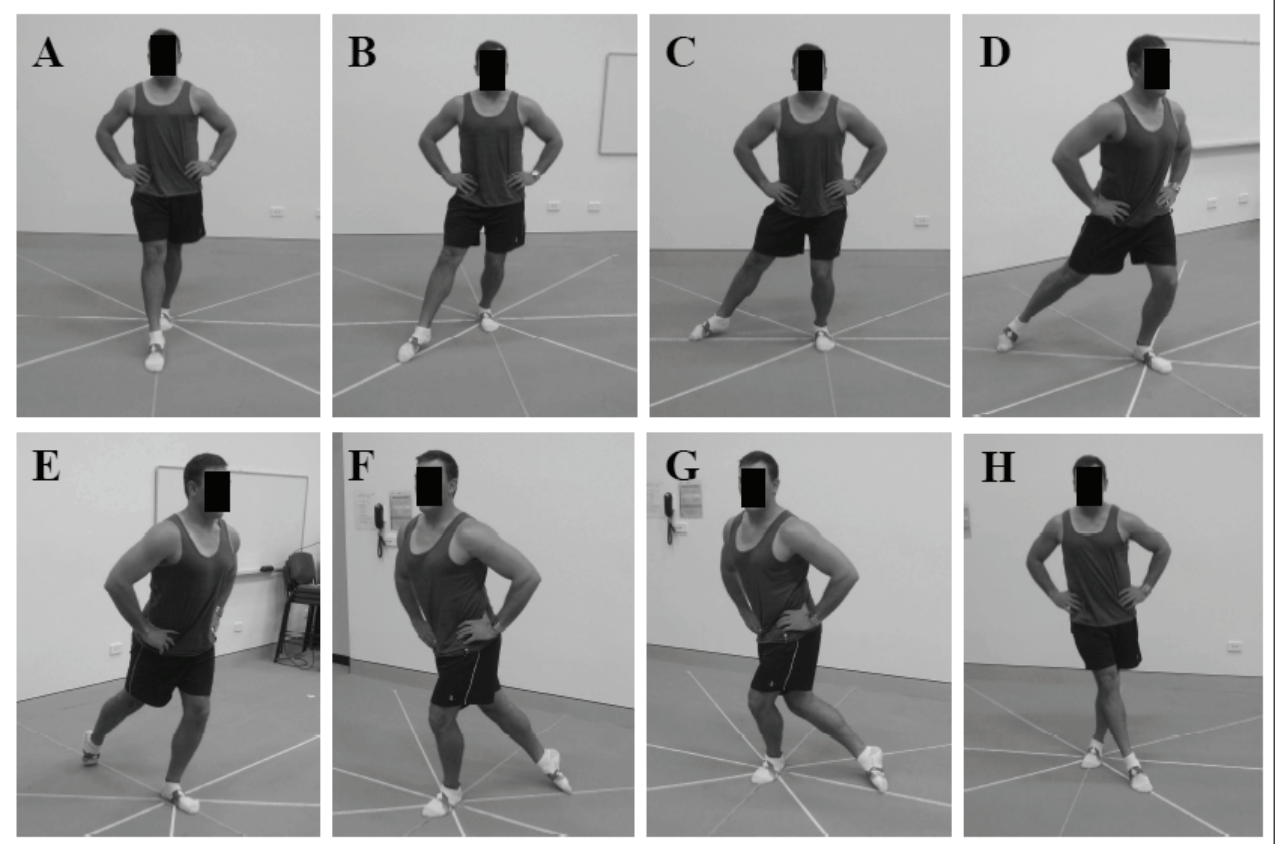

Fig. 2. Performance of the Star Excursion Balance Test with a left stance leg and right reach leg in the (A) anterior; (B) anterolateral; (C) lateral; (D) posterolateral; (E) posterior; (F) posteromedial; $(\mathrm{G})$ medial; and $(\mathrm{H})$ anteromedial directions.

als at the low velocity $\left(60^{\circ} / \mathrm{s}\right)$, followed by the intermediate velocity $\left(180^{\circ} / \mathrm{s}\right)$, and the high velocity $\left(240^{\circ} / \mathrm{s}\right)$, before completing the eccentric $\left(30^{\circ} / \mathrm{s}\right)$ strength assessment.

Once the subject was secured to the seat, they completed a warm-up of three submaximal repetitions at each testing velocity, with a 60-second rest interval between each set $[24,36]$. Following this, subjects completed four maximal repetitions at each of the testing speeds, with a 60 -second recovery between each velocity $[24,36]$. The leg that was tested first was randomized among subjects. Subjects held onto the seat handles during testing. To ensure maximal effort, a visual display of each repetition on the computer screen was shown, and verbal encouragement was provided to all subjects.

For each isokinetic angular velocity, the peak torque generated during each repetition was calculated within the Humac Norm software. The use of torque to measure isokinetic strength is the standard presentation of isokinetic muscle strength data [25]. The maximal value for torque for one of the repetitions within each set was used for analysis. These values were made relative for each subject by dividing the isokinetic strength measure by subject's body weight in kgf. This was done due to research indicating the importance of relative strength for team sport athletes [2,23]. Thus, torque was measured in Newton meters per kilogram of body mass $\left(\mathrm{Nm} \cdot \mathrm{kgf}^{-1}\right)$. Bilateral differences in torque were calculated as the percentage difference between the stronger and weaker legs [12,28]. The stronger leg was defined as the leg that generated greater relative torque at a given testing speed [28,30,40]. The formula stronger leg - weaker leg/stronger leg x 100 was used to derive the bilateral difference as a percentage.

\subsection{Data analysis}

All statistical analyses were computed using the Statistics Package for Social Sciences (Version 20.0; IBM Corporation, New York, USA). The data analysis for this study was modeled on previously established methods $[11,23,24]$. Subjects were split into two groups - better or lesser dynamic stability as measured by functional reach in the SEBT. Mean reach was determined for all subjects in the 16 distances, eight each for the right and left legs, and subjects were ranked according to this value. In order to ensure that the groups were composed of subjects with different levels of dynamic stability, a cut-off point was established through the formula mean $+(0.2 x$ standard deviation of the mean). Multiplying the between-subjects standard deviation by 0.2 provides the smallest worthwhile change in the mean for this sample [17]. Within the context of 
the current study, by providing a cut-off point above the overall functional reach mean of the study should ensure that subjects above this value would be superior. Therefore, subjects above this cut-off point were placed in the better group; subjects below this were placed in the lesser group.

A 1-way analysis of variance (ANOVA) was then used to determine whether there were significant differences between the dependent variables (i.e. reach distance, relative torque at each of the isokinetic velocities, differences between the legs for reach distances and relative torque of the better and lesser groups) [11, $23,24]$. The Levene statistic was used to determine homogeneity of variance of the data. An alpha level of $p \leqslant 0.05$ was chosen as the criterion for significance. Effect sizes (ES) were also calculated, where the difference between the means was divided by the pooled standard deviations [7]. For the purpose of this research, less than 0.2 was considered a trivial effect; 0.2 to 0.6 a small effect; 0.6 to 1.2 a moderate effect; 1.2 to 2.0 a large effect; 2.0 to 4.0 a very large effect; and 4.0 and above an extremely large effect [17].

\section{Results}

A group $(n=16)$ mean functional reach of $82.31 \pm$ $6.94 \%$ was calculated following data collection. This established a cut-off point of $83.70 \%$ for the better and lesser groups. Therefore, the better group consisted of 6 subjects (age $=22.00 \pm 2.28$ years; height $=1.80$ $\pm 0.04 \mathrm{~m}$; mass $=78.41 \pm 9.73 \mathrm{~kg}$; mean functional reach $=87.82 \pm 2.93 \%$ ), while the lesser group had 10 subjects (age $=24.10 \pm 6.54$ years; height $=1.77$ $\pm 0.09 \mathrm{~m}$; mass $=81.91 \pm 10.26 \mathrm{~kg}$; mean functional reach $=78.91 \pm 6.34 \%$ ). There was a significant difference in the mean functional reach across the 16 directions $(p=0.006$; ES $=1.80)$. There were no significant differences in age $(p=0.465 ; \mathrm{ES}=0.43)$, height ( $p=0.367$; $\mathrm{ES}=0.43)$, and mass $(p=0.511$; $\mathrm{ES}=0.35)$ between the groups. Subjects from the better group had a greater functional reach across all directions, and were significantly greater than the lesser group in nine directions (Table 1). The ES for these significant differences ranged from moderate to very large $(E S=1.16-2.23)$. Therefore, this split served the purpose of dividing the subjects into groups with different levels of dynamic stability as measured by functional reaching in the SEBT. The percentage differences between the reach attained for each stance leg is shown in Table 1; there were no significant differences be- tween the groups. There was a moderate effect (ES = 1.16) for the difference in anteromedial reach between the groups, with a larger disparity evident in the lesser group $(1.52 \pm 1.55 \%$ vs. $4.41 \pm 3.15 \%)$.

The relative torque values, and the percentage differences between the stronger and weaker legs for the better and lesser groups, are shown in Table 2. For the knee extensors of the right leg, the better group produced significantly ( $p=0.021 ; \mathrm{ES}=1.40)$ greater relative torque at the concentric speed of $180^{\circ}$ s $(2.13 \pm$ $0.16 \mathrm{Nm} \cdot \mathrm{kgf}^{-1}$ vs. $1.86 \pm 0.22 \mathrm{Nm} \cdot \mathrm{kgf}^{-1}$ ). Although neither reached significance, there was a large effect for the higher torque generated by the better group concentrically at $60^{\circ} \% \mathrm{~s}\left(3.07 \pm 0.23 \mathrm{Nm} \cdot \mathrm{kgf}^{-1}\right.$ vs. $2.73 \pm$ $\left.0.42 \mathrm{Nm} \cdot \mathrm{kgf}^{-1} ; p=0.090 ; \mathrm{ES}=1.59\right)$, and a moderate effect eccentrically at $30^{\circ} / \mathrm{s}\left(3.78 \pm 0.74 \mathrm{Nm} \cdot \mathrm{kgf}^{-1}\right.$ vs. $\left.2.97 \pm 0.78 \mathrm{Nm} \cdot \mathrm{kgf}^{-1} ; p=0.062 ; \mathrm{ES}=1.07\right)$. For the left leg, significantly greater relative torque was produced by the better group for the knee extensors at all speeds when compared to the lesser group. ES ranged from moderate to very large $(\mathrm{ES}=1.16-$ 2.23). There were no significant differences between the groups in the relative torque produced by the knee flexors for either the right or left legs. There were also no differences between the groups when considering the percent disparities in relative torque between the stronger and weaker legs.

\section{Discussion}

This is probably the first study to explore the relationship between isokinetic knee extensor and flexor strength and dynamic stability as measured by functional reaching in the SEBT, in strength-trained, healthy team sport athletes. The reach distances attained in this study were similar to those derived from a previous research $[13,34]$. This means that the biomechanics of the excursions completed by subjects from the current study would likely be similar to those previously described in the literature, and allows for certain assumptions about the kinematics and muscle activity of the reaching actions $[15,19]$. The results for this study indicated that subjects with better dynamic stability also tended to exhibit greater leg strength by producing greater knee extensor torque at the tested isokinetic speeds. The effects of strength on dynamic balance as measured by functional reaching were magnified when considering the left leg. These results have noteworthy implications for team sport and strength and conditioning coaches wishing to improve the dynamic stability of their athletes. 

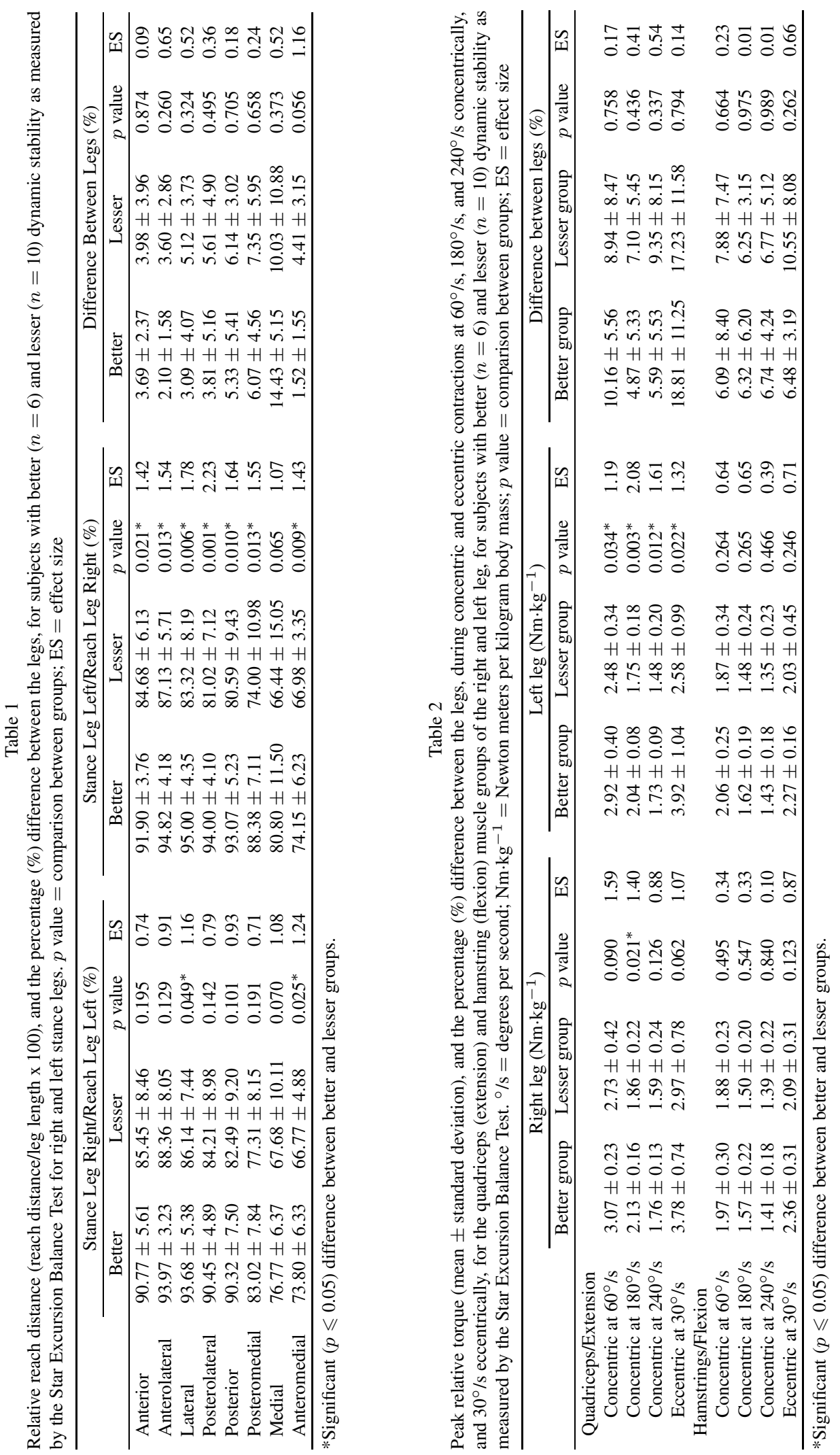
The subjects from the better group tended to have a greater functional reach when compared to the lesser group (Table 1). When considering the actions of the SEBT, the muscle groups about the knee are responsible for maintaining control of the stance leg when reaching [9]. Enhanced strength within these muscles would assist with dynamic stability maintenance, as greater knee flexion in the SEBT has been related to lower extremity strength [10]. Excursions in particular directions help illustrate the value of strength, in particular for the knee extensors, to dynamic stability. For example, the knee extensors are most active during excursions directed anteriorly [9], as they control the degree of knee flexion attained [14,34]. Therefore, strength of the knee extensors is essential for excursions in the anterior, anterolateral, and anteromedial directions during the SEBT. Subjects with better dynamic stability produced significantly greater relative torque concentrically with the knee extensors for both the right (at $180 \%$ s) and left (at $60 \% \mathrm{~s}, 180 \% \mathrm{~s}$, and $240^{\circ} / \mathrm{s}$ ) legs (Table 2 ). In conjunction with these strength results, the better group had a significantly greater anteromedial reach for both legs (Table 1).

Differences in functional reach between the groups were especially evident when the left leg was used for stance, and reaching was completed by the right leg. The better group had a significantly greater reach in seven of eight directions when the left leg was used for stance (Table 1). When comparing the legs based on isokinetic strength measures, the right leg for the better group demonstrated higher values in four out of the eight torque measurements. For the lesser group, the right leg was dominant in all eight torque measurements. Therefore, when using strength as the criterion $[28,30,40]$, the right leg was clearly dominant for the lesser group. For the better group, strength appeared to be more balanced between the legs. The influence of this strength difference for the left leg is illustrated not only by the better group consistently achieving greater excursions when this leg was used for stance, but also when considering the greater torque produced by the better group's left leg knee extensors when compared to the lesser group (Table 2).

Indeed, for the anterior and anterolateral directions, only excursions from when the left leg was used at stance were deemed statistically significant (Table 1). When performing anterior excursions, subjects lean backwards and extend the trunk, which causes an extension moment within the knee extensors [9], placing a greater eccentric stress on these muscles. The relative eccentric torque at $30^{\circ} \mathrm{s}$ produced by the better group for the knee extensors of the left leg was significantly greater than the lesser group (Table 2). Considering that better subjects exhibited greater functional reach in anterior directions when the left leg was used for stance, this highlights the interaction between functional reach and the measures of isokinetic strength from the current study. Improving eccentric strength within the knee extensors could contribute to enhanced dynamic stability for team sport athletes.

The significant functional reach measures for the left stance leg and right reach leg also predominated when considering other excursion directions. The better group had significantly greater reaches in the posterolateral, posterior, and posteromedial directions when the left leg was used for stance (Table 1). In the body position attained for these excursions, the trunk tends to be more flexed, which places a greater eccentric strain on the hamstrings [31]. Thus, the medial hamstring and biceps femoris tend to be more active during posterior excursions [9]. This would suggest that there should be significant differences between the groups in the relative torque generated by the knee flexors. Interestingly, this was not the case in the current study (Table 2). There was a moderate effect (ES = 0.71 ) for the greater knee flexor eccentric torque generated at $30 \%$ sy the better group, although the difference compared to the lesser group was not significant $(p=0.246)$. However, in order to remain stable during the unilateral squat activity required in the SEBT, there are co-contractions between the knee extensor and flexor muscle groups [9]. The stronger left leg knee extensors demonstrated by the better group could have contributed to the performance differences exhibited in the posterior excursions. These results provide further emphasis for the need to train the knee extensors to improve dynamic stability in team sport athletes.

The apparent strength balance between the legs for the better group is somewhat evidenced by smaller leg strength asymmetries in torque, although there were no significant differences when compared to the lesser group (Table 2). There was a moderate, but non-significant effect $(p=0.262, \mathrm{ES}=0.66)$ in the between-leg difference in relative torque produced eccentrically at $30 \%$ by the knee flexors (Table 2 ). The lesser group had a greater strength difference between the legs $(10.55 \pm 8.08 \%)$ when compared to the better group $(6.48 \pm 3.1 \%)$. As previously stated, the eccentric strength of the knee flexors is needed for the control of knee flexion during the SEBT [9,31]. In addition, eccentric knee flexor strength is important for other team sport-specific, unilateral activities, such as 
linear [21] and multidirectional [1,24] sprinting. Unilateral or cyclic-type movements (e.g. running), are predominant in team sport match-play, and can be limited by a weaker or restricted limb [6,24]. Ensuring a team sport athlete can achieve effective dynamic balance for both legs may improve athletic performance; specific strength training of the knee extensors and flexors could facilitate this. Nonetheless, between-leg strength differences of greater than $15 \%$ are generally viewed as being functionally significant $[3,8,20]$. For the most part, both groups were below this value for strength differences derived between the stronger and weaker legs. The only strength measure that could be considered as functionally significant was for the relative knee extensor eccentric torque generated at $30^{\circ} / \mathrm{s}$ for both groups (Table 2).

The results of this study indicate that subjects who exhibited better dynamic stability as measured by functional reaching in the SEBT also tended to have stronger knee extensors. This was especially true when considering the left leg as the stance leg in the SEBT. These results highlight the value of the knee extensors for unilateral dynamic stability, and suggest that team sport athletes should improve the relative strength of these muscles to aid in stability in their chosen sport. Although the results from the current study emphasize the need for stronger knee extensors to enhance dynamic stability, the contribution of the knee flexors should not be ignored. Both muscles groups should be trained accordingly. Previous research has shown that dynamic stability can be improved following training involving a variety of exercises, such as abdominal and core training, plyometrics, and specific lowerlimb strength exercises [10,22]. Future research should analyze whether training for specific improvements in strength for the muscle groups about the knee can also improve dynamic stability.

\section{Conclusion}

Considering the results of the current study, subjects with better dynamic stability, as shown through greater lower-limb functional reach distances, demonstrated greater knee extensor strength. Better subjects generated greater relative knee extensor torque concentrically at $60 \% \mathrm{~s}, 180 \% \mathrm{~s}$, and $240 \%$ s, and eccentrically at $30 \%$ s. The left leg in particular was stronger for the better group, and the effects of knee extensor strength on dynamic stability were especially pronounced for the left leg. When this leg was used for stance during the SEBT, subjects with better dynamic stability reached significantly further across most directions when compared to lesser subjects. This greater reach was supported superior strength in the left leg. Increased strength in knee extensors in particular, but also the knee flexors, will aid in the control of unilateral support during actions that require dynamic stability. Team sport and strength and conditioning coaches should ensure that knee extensor and flexor strength is sufficient to enhance dynamic stability. Furthermore, coaches should make certain that each leg possesses sufficient strength to support dynamic stability.

\section{Acknowledgements}

This research project received no external financial assistance. None of the authors have any conflict of interest. The authors would like to thank our subjects for their contribution to the study.

\section{References}

[1] M.A. Anderson, J.H. Gieck, D. Perrin, A. Weltman, R. Rutt and C. Denegar. The relationships among isometric, isotonic, and isokinetic concentric and eccentric quadriceps and hamstring force and three components of athletic performance. $J$ Orthop Sports Phys Ther 14 (1991), 114-20.

[2] D. Baker and S. Nance. The relation between running speed and measures of strength and power in professional rugby league players. J Strength Cond Res 13 (1999), 230-5.

[3] K. Bennell, H. Wajswelner, P. Lew, A. Schall-Riaucour, S. Leslie, D. Plant and J. Cirone. Isokinetic strength testing does not predict hamstring injury in Australian Rules footballers. Br J Sports Med 32 (1998), 309-14.

[4] K.E. Berg. Comprehensive training for sport: implications for the strength and conditioning professional. Strength Cond J 28 (2006), 10-8.

[5] E. Bressel, J.C. Yonker, J. Kras and E.M. Heath. Comparison of static and dynamic balance in female collegiate soccer, basketball, and gymnastics athletes. J Athl Training 42 (2007), 42-6.

[6] M. Brughelli, J. Cronin, J. Mendiguchia, D. Kinsella and K. Nosaka. Contralateral leg deficits in kinetic and kinematic variables during running in Australian rules football players with previous hamstring injuries. J Strength Cond Res 24 (2010), 2539-44.

[7] J. Cohen. Statistical power analysis for the behavioral sciences 2nd ed. Hillsdale, New Jersey: Lawrence Earlbaum Associates; 1988.

[8] M. Dauty, M. Dupré, M. Potiron-Josse and C. Dubois. Identification of mechanical consequences of jumper's knee by isokinetic concentric torque measurement in elite basketball players. Isokinet Exerc Sci 15 (2007), 37-41.

[9] J.E. Earl and J. Hertel. Lower-extremity muscle activation during the Star Excursion Balance Tests. J Sport Rehabil 10 (2001), 93-104. 
[10] A. Filipa, R. Byrnes, M.V. Paterno, G.D. Myer and T.E. Hewett. Neuromuscular training improves performance on the Star Excursion Balance Test in young female athletes. $\mathrm{J} \mathrm{Or}$ thop Sports Phys Ther 40 (2010), 551-8.

[11] D.M. Frost and J.B. Cronin. Stepping back to improve sprint performance: a kinetic analysis of the first step forwards. $J$ Strength Cond Res 25 (2011), 2721-8.

[12] A. Gioftsidou, A. Beneka, P. Malliou, G. Pafis and G. Godolias. Soccer players' muscular imbalances: restoration with an isokinetic strength training program. Percept Mot Skills 103 (2006), 151-9.

[13] P.A. Gribble and J. Hertel. Considerations for normalizing measures of the star excursion balance test. Meas Phys Educ Exerc Sci 7 (2003), 89-100.

[14] P.A. Gribble, J. Hertel, C.R. Denegart and W.E. Buckley. The effects of fatigue and chronic ankle instability on dynamic postural control. J Athl Training 39 (2004), 321-.

[15] L. Hardy, K. Huxel, J. Brucker and T. Nesser. Prophylactic ankle braces and star excursion balance measures in healthy volunteers. J Athl Training 43 (2008), 347-51.

[16] J. Hertel, S.J. Miller and C.R. Denegar. Intratester and intertester during the Star Excursion Balance Tests. J Sport Rehabil 9 (2000), 104.

[17] W.G. Hopkins. How to interpret changes in an athletic performance test. Sportscience 8 (2004), 1-7.

[18] J. Iga, K. George, A. Lees and T. Reilly. Cross-sectional investigation of indices of isokinetic leg strength in youth soccer players and untrained individuals. Scand J Med Sci Sports 19 (2009), 714-9.

[19] N.L. Kahle and P.A. Gribble. Core stability training in dynamic balance testing among young, healthy adults. Athl Training Sport Health Care 1 (2009), 65-73.

[20] J.J. Knapik, C.L. Bauman, B.H. Jones, J.M. Harris and L. Vaughan. Preseason strength and flexibility imbalances associated with athletic injuries in female collegiate athletes. $\mathrm{Am}$ J Sports Med 19 (1991), 76-81.

[21] H. Kyröläinen, J. Avela and P.V. Komi. Changes in muscle activity with increasing running speed. J Sports Sci 23 (2005), 1101-9.

[22] V.J. Leavey, M.A. Sandrey and G. Dahmer. Comparative effects of 6-week balance, gluteus medius strength, and combined programs on dynamic postural control. J Sport Rehabil 19 (2010), 268-87.

[23] R.G. Lockie, A.J. Murphy, T.J. Knight and X.A.K. Janse de Jonge. Factors that differentiate acceleration ability in field sport athletes. J Strength Cond Res 25 (2011), 2704-14.

[24] R.G. Lockie, A.B. Schultz, M.D. Jeffriess and S.J. Callaghan. The relationship between bilateral differences of knee flexor and extensor isokinetic strength and multi-directional speed. Isokinet Exerc Sci 20 (2012), 211-9.

[25] H. Lund, K. Sondergaard, T. Zachariassen, R. Christensen, P. Bulow, M. Henriksen, E.M. Bartels, B. Danneskiold-Samsoe and $\mathrm{H}$. Bliddal. Learning effect of isokinetic measurements in healthy subjects, and reliability and comparability of Biodex and Lido dynamometers. Clin Physiol Funct Imaging 25 (2005), 75-82.
[26] D. Moxley Scarborough, D.E. Krebs and B.A. Harris. Quadriceps muscle strength and dynamic stability in elderly persons. Gait Posture 10 (1999), 10-20.

[27] M.A. Newman, K.M. Tarpenning and F.E. Marino. Relationships between isokinetic knee strength, single-sprint performance, and repeated-sprint ability in football players. $J$ Strength Cond Res 18 (2004), 867-72.

[28] R.U. Newton, A. Gerber, S. Nimphius, J.K. Shim, B.K. Doan, M. Robertson, D.R. Pearson, B.W. Craig, K. Hakkinen and W.J. Kraemer. Determination of functional strength imbalance of the lower extremities. J Strength Cond Res 20 (2006), 971-7.

[29] J.R. Nocera, T. Buckley, D. Waddell, M.S. Okun and C.J. Hass. Knee extensor strength, dynamic stability, and functional ambulation: are they related in Parkinson's disease? Arch Phys Med Rehabil 91 (2010), 589-95.

[30] K.D. Nunn and J.L. Mayhew. Comparison of three methods of assessing strength imbalances at the knee. J Orthop Sports Phys Ther 10 (1988), 134-7.

[31] Y. Ohkoshi, K. Yasuda, K. Kaneda, T. Wada and M. Yamanaka. Biomechanical analysis of rehabilitation in the standing position. Am J Sports Med 19 (1991), 605-11.

[32] L.C. Olmsted, C.R. Carcia, J. Hertel and S.J. Shultz. Efficacy of the Star Excursion Balance Tests in detecting reach deficits in subjects with chronic ankle instability. J Athl Training $\mathbf{3 7}$ (2002), 501-6.

[33] B.L. Riemann, K.M. Guskiewicz and E.W. Shields. Relationship between clinical and forceplate measures of postural stability. J Sport Rehabil 8 (1999), 71-82.

[34] R. Robinson and P. Gribble. Kinematic predictors of performance on the Star Excursion Balance Test. J Sport Rehabil 17 (2008), 347-57.

[35] A. Sarshin, S. Mohammadi, H.B.P. Shahrabad and M. Sedighi. The effects of functional fatique on dynamic postural control of badminton players. Biol Exerc 7 (2011), 25-34.

[36] B.L. Warren and K.K. Longwell. Rest period effect on peak torque in female collegiate and recreational athletes. Isokinet Exerc Sci 18 (2010), 179-84.

[37] E.A. Wikstrom, M.E. Powers and M.D. Tillman. Dynamic stabilization time after isokinetic and functional fatigue. $J$ Athl Training 39 (2004), 247-53.

[38] E.A. Wikstrom, M.D. Tillman, A.N. Smith and P.A. Borsa. A new force-plate technology measure of dynamic postural stability: The dynamic postural stability index. J Athl Training 40 (2005), 305-9.

[39] M.R. Wilhite, E.R. Cohen and S.C. Wilhite. Reliability of concentric and eccentric measurements of quadriceps performance using the KIN-COM dynamometer: The effect of testing order for three different speeds. J Orthop Sports Phys Ther 15 (1992), 175-82.

[40] T. Yamamoto. Relationship between hamstring strains and leg muscle strength. A follow-up study of collegiate track and field athletes. J Sports Med Phys Fit 33 (1993), 194-9. 
Copyright of Isokinetics \& Exercise Science is the property of IOS Press and its content may not be copied or emailed to multiple sites or posted to a listserv without the copyright holder's express written permission. However, users may print, download, or email articles for individual use. 